\title{
PENGELOMPOKAN MINAT BACA MAHASISWA MENGGUNAKAN METODE K-MEANS
}

\author{
Widya Safira Azis ${ }^{1}$ dan Dedy Atmajaya ${ }^{2}$ \\ 1safiraazis18@gmail.com dan 2dedy.atmajaya@umi.ac.id \\ 1,2Teknik Informatika Universitas Muslim Indonesia
}

\begin{abstract}
Abstrak
Pengelompokkan minat baca mahasiswa berdasarkan kriteria buku yang dibaca, buku yang dipinjam, dan juga mempertimbangkan jumlah stok buku yang tersedia dapat membantu dalam proses penambahan koleksi buku yang telah ada pada perpustakaan Utsman Bin Affan UMI. Salah satu cara untuk mengelola data tersebut yaitu menggunakan data mining dengan memanfaatkan metode $\mathrm{K}$ Means. Data buku dikelompokkan menjadi 3 cluster yaitu prioritas, dipertimbangkan, dan tidak diprioritaskan dalam perencanaan penambahan koleksi buku. Hasil dari penelitian ini adalah cluster dengan nilai terbesar pada centroid akhir merupakan cluster yang direkomendasikan dalam perencanaan penambahan koleksi buku.
\end{abstract}

Kata kunci: clustering, $k$-means, data, perpustakaan

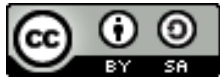

ILKOM Jurnal IImiah work is licensed under a CCA-SA 4.0 International License.

\section{Pendahuluan}

Perpustakaan adalah suatu unit kerja yang berupa tempat menyimpan koleksi bahan pustaka yang diatur secara sistematis dengan cara tertentu untuk dipergunakan secara berkesinambungan oleh pemakainya sebagai sumber informasi [2].

Perpustakaan Utsman Bin Affan saat ini, memiliki koleksi buku \pm 22.540 Judul 82.285 Exp, dalam bidang ilmu : karya umum, filsafat dan psikologi, agama, ilmu-ilmu sosial, bahasa, ilmu-ilmu murni (pasti/alam), ilmu-ilmu terapan, kesenian, hiburan, olahraga, kesusastraan, geografi dan sejarah umum. Agar koleksi buku di dalam perpustakaan dapat dimanfaatkan secara maksimal, harus diterapkan suatu sistem untuk mengatur koleksi buku tersebut. Saat ini, sistem yang diterapkan di perpustakaan Utsman Bin Affan Universitas Muslim Indonesia berjalan kurang efektif. Ini terlihat dari mulai tahap perencanaan yang meliputi pemilihan hingga penambahan koleksi buku yang tidak maksimal.

Dalam proses penambahan koleksi buku, pihak perpustakaan hanya menjadikan statistik peminjaman buku terlaris sebagai acuan dalam peningkatan jumlah koleksi buku yang telah ada, tanpa mempertimbangkan buku mana yang menjadi prioritas utama untuk ditingkatkan koleksinya. Padahal, dari tahap pemilihan koleksi, dapat dilihat kualitas perpustakaan dalam memberikan informasi kepada pengguna. Sehingga, secara tidak langsung, dapat menimbulkan pengaruh yang sangat besar, yaitu mulai berkurangnya minat baca dari pengguna perpustakaan dalam memanfaatkan koleksi yang ada.

Dalam memaksimalkan proses penambahan koleksi buku di perpustakaan Utsman Bin Affan UMI, maka dibutuhkan sebuah sistem yang digunakan untuk mengelola data tersebut secara komputerisasi. Salah satu cara untuk mengelola data tersebut yaitu dengan menggunakan data mining. Dengan memanfaatkan metode k-means pada data mining, setiap data buku akan dikelompokkan menjadi 3 cluster. yaitu prioritas tinggi, dipertimbangkan, dan bukan prioritas untuk perencanaan penambahan koleksi buku. Hasil yang didapatkan yaitu, untuk data buku yang berada pada cluster prioritas tinggi, inilah yang akan dijadikan sebagai bahan evaluasi bagi pihak perpustakaan dalam meningkatkan koleksi buku yang sudah ada.

Tujuan utama dari penelitian ini ialah untuk mendesain aplikasi pengelompokkan minat baca pada Perpustakaan Utsman Bin Affan UMI, yang diharapkan dapat membantu pihak perpustakaan dalam memecahkan masalah penambahan koleksi buku dengan tepat dan cepat.

\section{Landasan Teori}

\subsection{Algoritma K-Means Clustering}

K-Means termasuk dalam partitioning clustering yaitu setiap data harus masuk dalam cluster tertentu dan memungkinkan bagi setiap data yang termasuk dalam cluster tertentu pada suatu tahapan proses, pada tahapan berikutnya berpindah ke cluster yang lain. $K$-Means memisahkan data ke $k$ daerah 
bagian yang terpisah, dimana $k$ adalah bilangan integer positif. Algoritma K-Means sangat terkenal karena kemudahan dan kemampuannya untuk mengklaster data besar dan outlier dengan sangat cepat. Secara sederhana algoritma K-Means adalah sebagai berikut [5]:

1. Tentukan $k$ sebagai jumlah cluster yang ingin dibentuk.

2. Bangkitkan $k$ centroid (titik pusat cluster) awal secara random atau ditentukan secara default.

3. Hitung masing-masing jarak setiap data ke masing-masing centroid.

4. Setiap data memilih centroid yang terdekat.I

5. Tentukan posisi centroid baru dengan cara menghitung nilai rata-rata dari data-data yang memilih pada centroid yang sama.

6. Kembali ke langkah 3 jika posisi centroid baru dengan centroid lama tidak sama [1].

\subsection{Penerapan Algoritma K-Means}

Algoritma K-Means:

1. Membaca data buku yang telah dikategorikan.

2. Menentukan jumlah atribut $=3$, dan jumlah cluster $=3$.

3. Menset nilai awal centroid secara default.

4. Melakukan klasterisasi dengan mengelompokkan data berdasarkan jarak terdekat.

5. Jika data buku pinjam, baca dan stok buku ditambahkan, maka akan terjadi perubahan data klasterisasi. Jika kondisi memenuhi maka sistem akan melakukan klasterisasi kembali dengan mengelompokkan data berdasarkan jarak terdekat.

6. Klasterisasi akan dilakukan sampai hasilnya konvergen dan tidak ada lagi perpindahan data.

\subsection{Pengukuran Kemiripan dengan Jarak atau Distance}

Langkah penting dalam clustering adalah menentukan perhitungan jarak / distance measure, yang sangat menentukan perhitungan bagaimana kemiripan antar dua elemen. Untuk menghitung jarak / distance measure, dapat menggunakan rumus Euclidean Distance yaitu [7] :

$$
d(x, y)=\sqrt{\left(x_{1}-s_{1}\right)^{2}+\left(y_{2}-t_{2}\right)^{2}} \cdots \cdots \cdots
$$

Pada persamaan 1 ,

$(\mathbf{x}, \mathbf{y}) \quad$ : titik koordinat objek

$(\mathbf{s , t}) \quad$ : titik koordinat centroid

$\mathbf{d}(\mathbf{x}, \mathbf{y})$ : Euclidean distance yaitu jarak antara data pada titik $\mathbf{x}$ dan titik y menggunakan kalkulasi matematika (Bezdek, 1981). Misalnya : titik data bisa didefinisikan sebagai Person dalam database, sementara atributnya adalah Age, Height, Weight, Income.

\section{Metode}

Pada penelitian ini, dilakukan beberapa tahapan yang saling berkaitan antara satu tahap dengan tahap lainnya. Flowchart tahapan penelitian yang dilakukan dapat dilihat pada gambar 1 [3].

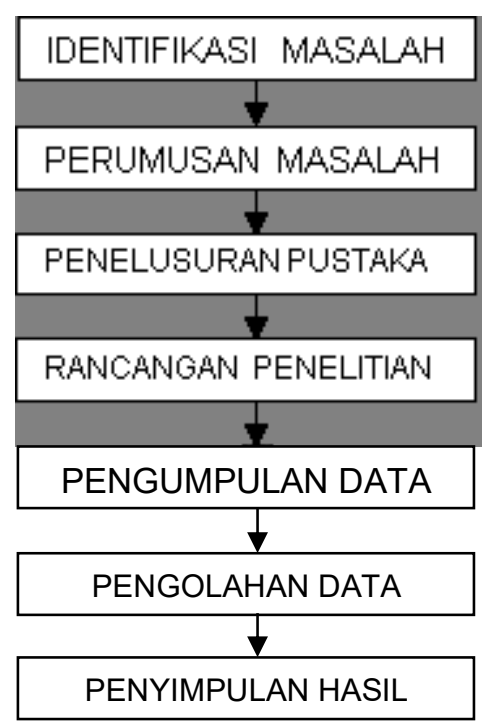

Gambar 1. Flowchart Tahapan Penelitian [3] 
Berdasarkan Gambar 1. dapat dilihat bahwa tahap pertama yang dilakukan dalam penelitian ini adalah identifikasi masalah. Identifikasi masalah dilakukan untuk melihat dengan jelas tujuan dan sasaran dari penelitian yang akan dilakukan. Masalah penelitian dipilih berdasarkan beberapa pertimbangan, antara lain sisi waktu, biaya maupun kontribusi diberikan bagi pengembangan ilmu pengetahuan dan teknologi. Tahap selanjutnya adalah perumusan masalah. Perumusan masalah perlu dilakukan agar proses penelitian lebih terarah sehingga dapat memberikan petunjuk untuk pengumpulan data serta pencarian metode yang tepat untuk pemecahan masalah tersebut. Setelah merumuskan masalah, tahap berikutnya yang dilakukan adalah penelusuran pustaka. Pada tahap ini dilakukan pencarian pustaka dan pengumpulan informasi yang berhubungan dengan penelitian. Penelusuran pustaka berguna untuk menghindari duplikasi dari pelaksanaan penelitian.

Tahap berikutnya yaitu rancangan penelitian. Rancangan penelitian merupakan rencana menyeluruh dari penelitian mencakup hal-hal yang akan dilakukan dalam penelitian ini. Adapun rancangan penelitian dari penelitian ini adalah rentang waktu penelitian dilakukan, teknik pengumpulan data dan pengolahan data. Data yang dikumpulkan dalam tahap pengumpulan data ini merupakan data sekunder yang diperoleh melalui wawancara di Perpustakaan Utsman Bin Affan untuk mendapatkan data yang diperlukan dalam penelitian ini dan data primer yaitu data yang berasal dari pihak yang bersangkutan atau langsung dari pegawai yang bertugas. Data tersebut kemudian diolah yang berfungsi untuk sistem yang akan dibangun. Hasil dari pengolahan data yang dilakukan melalui proses pengujian akan digunakan dalam tahap penyimpulan hasil sebagai kesimpulan dari penelitian.

\section{Hasil}

Perhitungan dalam modul k-means menggunakan data yang terdiri dari 10 data dengan kategori buku dengan kriteria : buku yang dipinjam, buku yang dibaca dan stok buku. Percobaan dilakukan dengan menggunakan parameter-paremeter berikut : Jumlah cluster : 3, Jumlah data : 10.

Tabel 1. Data Ketegori Buku

\begin{tabular}{cclccc}
\hline No & $\begin{array}{c}\text { No Kelas } \\
\text { Buku }\end{array}$ & \multicolumn{1}{c}{ Kategori buku } & Stok & Pinjam & Baca \\
\hline 1 & 0 & Karya Umum & 33 & 3 & 1 \\
2 & 100 & Filsafat dan Psikologi & 22 & 1 & 1 \\
3 & 200 & Agama & 146 & 17 & 9 \\
4 & 300 & Ilmu Sosial & 102 & 12 & 1 \\
5 & 400 & Bahasa & 18 & 5 & 2 \\
6 & 500 & Ilmu Murni & 34 & 3 & 1 \\
7 & 600 & Ilmu Terapan & 301 & 26 & 8 \\
8 & 700 & Kesenian, Hiburan, Olah Raga & 11 & 2 & 2 \\
9 & 800 & Kesusastraan & 9 & 1 & 2 \\
10 & 900 & Geografi dan Sejarah Umum & 2 & 1 & 2 \\
\hline
\end{tabular}

Tabel 1. Merupakan data yang digunakan untuk melakukan percobaan perhitungan manual.

Berikut adalah langkah-langkah algoritma dalam modul K-Means:

1. Pusat awal klaster didapatkan dari data sendiri bukan dengan menentukan titik baru. Untuk kasus ini terdapat 3 pusat data yaitu centroid 1 , centroid 2, centroid 3 . Centroid $1=$ Rendah, Centroid $2=$ Sedang, Centroid 3 = Tinggi.

2. Perhitungan jarak dengan pusat klaster Untuk mengukur jarak antara data dengan pusat klaster digunakan Euclidian distance. Algoritma perhitungan jarak data dengan pusat klaster

a. Ambil nilai data dan nilai pusat klaster

b. Hitung Euclidian distance data dengan tiap pusat klaster

3. Pengelompokkan data jarak hasil perhitungan akan dilakukan perbandingan dan dipilih jarak terdekat antara data dengan pusat klaster, jarak ini menunjukkan bahwa data tersebut berada dalam satu kelompok dengan pusat klaster terdekat. Algoritma pengelompokkan data :

a. Ambil nilai jarak tiap pusat klaster dengan data

b. Cari nilai jarak terkecil

c. Kelompokkan data dengan pusat klaster yang memiliki jarak terkecil. 
4. Penentuan pusat klaster baru Untuk mendapatkan pusat klaster baru bisa dihitung dari rata-rata nilai anggota klaster dan pusat klaster. Pusat klaster yang baru digunakan untuk melakukan iterasi selanjutnya, jika hasil yang didapatkan belum konvergen. Proses iterasi akan berhenti jika telah memenuhi maksimum iterasi yang dimasukan oleh user atau hasil yang dicapai sudah konvergen (pusat klaster baru sama dengan pusat klaster lama).

Dari algoritma di atas maka dapat dilakukan perhitungan sebagai berikut :

\section{Penentuan Pusat Klaster Awal}

1. Untuk pusat cluster buku pinjam:

Rendah : 2 , sedang : 4 , tinggi : 6 .

2. Untuk pusat cluster buku baca:

Rendah : 2 , sedang : 4, tinggi : 6 .

3. Untuk pusat cluster stok:

Rendah : 100 , sedang : 200, tinggi : 300 .

Hasil Perhitungan Iterasi-1 :

Tabel 2. Iterasi - 1

\begin{tabular}{|c|c|c|c|c|c|c|c|c|c|c|c|c|c|c|}
\hline \multirow{2}{*}{ No } & \multirow{2}{*}{$\begin{array}{c}\text { No } \\
\text { Kelas }\end{array}$} & \multirow{2}{*}{ Nama } & \multicolumn{3}{|c|}{ Centroid 1} & \multicolumn{3}{|c|}{ Centroid 2} & \multicolumn{3}{|c|}{ Centroid 3} & \multirow{2}{*}{$\begin{array}{c}\text { Centroid } \\
1 \\
\end{array}$} & \multirow{2}{*}{$\begin{array}{l}\text { Centroid } \\
2\end{array}$} & \multirow{2}{*}{$\begin{array}{c}\text { Centroid } \\
3\end{array}$} \\
\hline & & & 300.0 & 2.0 & 2.0 & 200.0 & 4.0 & 4.0 & 100.0 & 6.0 & 6.0 & & & \\
\hline 1 & 0 & Karya Umum & & 33 & & & 3 & & & 1 & & & & Ok \\
\hline 2 & 100 & $\begin{array}{l}\text { Filsafat dan } \\
\text { Psikologi }\end{array}$ & & 22 & & & 1 & & & 1 & & & & Ok \\
\hline 3 & 200 & Agama & & 146 & & & 17 & & & 9 & & & & Ok \\
\hline 4 & 300 & Ilmu Sosial & & 102 & & & 12 & & & 1 & & & & Ok \\
\hline 5 & 400 & Bahasa & & 18 & & & 5 & & & 2 & & & & Ok \\
\hline 6 & 500 & IImu Murni & & 34 & & & 3 & & & 1 & & & & Ok \\
\hline 7 & 600 & IImu Terapan & & 301 & & & 26 & & & 8 & & & Ok & \\
\hline 8 & 700 & $\begin{array}{l}\text { Kesenian, } \\
\text { Hiburan, Olah } \\
\text { Raga }\end{array}$ & & 11 & & & 2 & & & 2 & & & & Ok \\
\hline 9 & 800 & Kesusastraan & & 9 & & & 1 & & & 2 & & & & Ok \\
\hline 10 & 900 & $\begin{array}{l}\text { Geografi dan } \\
\text { Sejarah Umum }\end{array}$ & & 2 & & & 1 & & & 2 & & & & Ok \\
\hline
\end{tabular}

Untuk menghitung jarak pusat klaster, menggunakan rumus Euclidean Distance [4].

$$
\mathrm{d}=|x-y| \sqrt{\sum_{i=1}^{n}\left|x_{i}-y_{i}\right|^{2}}
$$

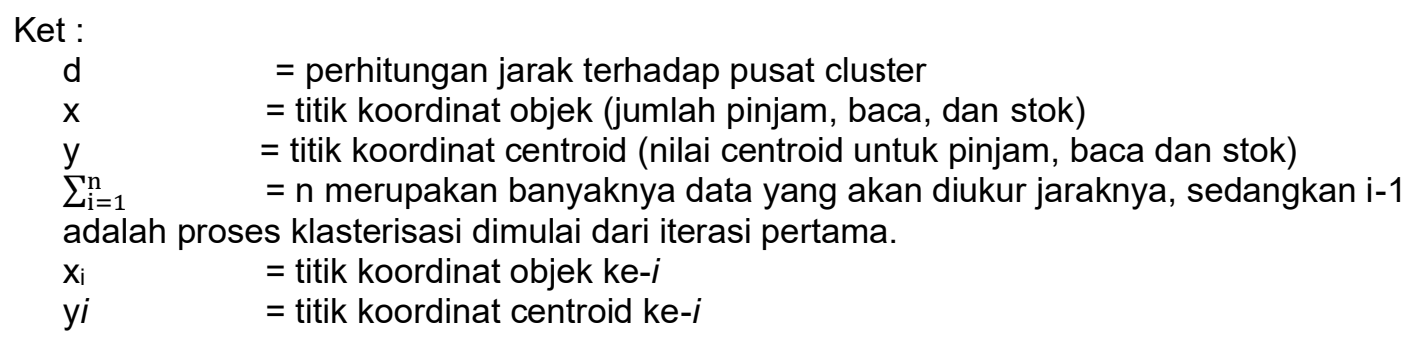

Jarak hasil perhitungan akan dilakukan perbandingan dan dipilih jarak terdekat antara data dengan pusat klaster, jarak ini menunjukkan bahwa data tersebut berada dalam satu kelompok dengan pusat klaster terdekat. Dari hasil perhitungan didapatlah jarak terdekat dengan pusat data yaitu 1 pada centroid 1, 0 pada centroid 2, dan 9 pada centroid 3 sehingga terbentuklah centroid baru.

Rumus yang digunakan untuk mencari centroid baru. yaitu [4]:

$$
\frac{x 1+x 2+\cdots x n, \quad y 1+y 2+\cdots y n}{n}
$$

Ket :

$\mathrm{x} 1+\mathrm{x} 2+\ldots \mathrm{xn}$ adalah titik koordinat $\mathrm{x}$ pada data yang tergabung dalam suatu centroid $\mathrm{y} 1+\mathrm{y} 2+\ldots$ yn adalah titik koordinat y pada data yang tergabung dalam suatu centroid. $\mathrm{n}$ adalah banyaknya data yang tergabung dalam suatu pusat data (centroid). 
ILKOM Jurnal Ilmiah Volume 8 Nomor 2 (Agustus 2016)

Hasil Perhitungan Iterasi - 2 :

Tabel 2. Iterasi - 2

\begin{tabular}{|c|c|c|c|c|c|c|c|c|c|c|c|c|c|c|}
\hline \multirow{2}{*}{ No } & \multirow{2}{*}{$\begin{array}{l}\text { No } \\
\text { Kelas }\end{array}$} & \multirow{2}{*}{ Nama } & \multicolumn{3}{|c|}{ Centroid 1} & \multicolumn{3}{|c|}{ Centroid 2} & \multicolumn{3}{|c|}{ Centroid 3} & \multirow{2}{*}{$\begin{array}{c}\text { Centroid } \\
1\end{array}$} & \multirow{2}{*}{$\begin{array}{c}\text { Centroid } \\
2\end{array}$} & \multirow{2}{*}{$\begin{array}{c}\text { Centroid } \\
3\end{array}$} \\
\hline & & & 301.0 & 26.0 & 8.0 & 0.0 & 0.0 & 0.0 & 41.9 & 5.0 & 2.3 & & & \\
\hline 1 & 0 & Karya Umum & & 269.1 & & & 33.2 & & & 9.2 & & & & Ok \\
\hline 2 & 100 & $\begin{array}{l}\text { Filsafat dan } \\
\text { Psikologi }\end{array}$ & & 280.2 & & & 22.0 & & & 20.3 & & & & Ok \\
\hline 3 & 200 & Agama & & 155.3 & & & 147.3 & & & 105.0 & & & & Ok \\
\hline 4 & 300 & Ilmu Sosial & & 199.6 & & & 102.7 & & & 60.5 & & & & Ok \\
\hline 5 & 400 & Bahasa & & 283.8 & & & 18.8 & & & 23.9 & & & Ok & \\
\hline 6 & 500 & Ilmu Murni & & 268.1 & & & 34.2 & & & 8.3 & & & & Ok \\
\hline 7 & 600 & Ilmu Terapan & & 0.0 & & & 302.2 & & & 260.0 & & Ok & & \\
\hline 8 & 700 & $\begin{array}{l}\text { Kesenian, } \\
\text { Hiburan, Olah } \\
\text { Raga }\end{array}$ & & 291.1 & & & 11.4 & & & 31.0 & & & Ok & \\
\hline 9 & 800 & Kesusastraan & & 293.1 & & & 9.3 & & & 33.1 & & & Ok & \\
\hline 10 & 900 & $\begin{array}{l}\text { Geografi dan } \\
\text { Sejarah Umum }\end{array}$ & & 300.1 & & & 3.0 & & & 40.1 & & & Ok & \\
\hline
\end{tabular}

Hasil Perhitungan Iterasi - 3 :

Tabel 3. Iterasi - 3

\begin{tabular}{|c|c|c|c|c|c|c|c|c|c|c|c|c|c|c|}
\hline \multirow[b]{2}{*}{ No } & \multirow{2}{*}{$\begin{array}{c}\text { No } \\
\text { Kelas }\end{array}$} & \multirow[b]{2}{*}{ Nama } & \multicolumn{3}{|c|}{ Centroid 1} & \multicolumn{3}{|c|}{ Centroid 2} & \multicolumn{3}{|c|}{ Centroid 3} & \multirow{2}{*}{$\begin{array}{c}\text { Centroid } \\
1\end{array}$} & \multirow{2}{*}{$\begin{array}{c}\text { Centroid } \\
2\end{array}$} & \multirow{2}{*}{$\begin{array}{c}\text { Centroid } \\
3\end{array}$} \\
\hline & & & $\begin{array}{c}301.0 \\
0\end{array}$ & \begin{tabular}{|c|}
26.0 \\
0
\end{tabular} & 8.00 & $\begin{array}{c}10.0 \\
0\end{array}$ & \begin{tabular}{|c|}
2.2 \\
5
\end{tabular} & 2.00 & $\begin{array}{c}67.4 \\
0\end{array}$ & 7.20 & 2.60 & & & \\
\hline 1 & 0 & Karya Umum & & 199.61 & & & 92.52 & & & 34.97 & & & & Ok \\
\hline 2 & 100 & $\begin{array}{l}\text { Filsafat dan } \\
\text { Psikologi }\end{array}$ & & 155.26 & & & 136.9 & & & 79.47 & & & & Ok \\
\hline 3 & 200 & Agama & & 280.21 & & & 12.11 & & & 45.85 & & & Ok & \\
\hline 4 & 300 & Ilmu Sosial & & 269.08 & & & 23.03 & & & 34.69 & & & Ok & \\
\hline 5 & 400 & Bahasa & & 283.84 & & & 8.46 & & & 49.45 & & & Ok & \\
\hline 6 & 500 & IImu Murni & & 268.08 & & & 24.03 & & & 33.70 & & & Ok & \\
\hline 7 & 600 & IImu Terapan & & 0.00 & & & 292.0 & & & 234.42 & & Ok & & \\
\hline 8 & 700 & $\begin{array}{l}\text { Kesenian, } \\
\text { Hiburan, Olah } \\
\text { Raga }\end{array}$ & & 291.05 & & & 1.03 & & & 56.64 & & & Ok & \\
\hline 9 & 800 & Kesusastraan & & 293.13 & & & 1.60 & & & 58.73 & & & Ok & \\
\hline 10 & 900 & $\begin{array}{l}\text { Geografi dan } \\
\text { Sejarah Umum }\end{array}$ & & 300.10 & & & 8.10 & & & 65.70 & & & Ok & \\
\hline
\end{tabular}

Hasil Perhitungan Iterasi - 4 :

Tabel 4. Iterasi - 4

\begin{tabular}{|c|c|c|c|c|c|c|c|c|c|c|c|c|c|c|}
\hline \multirow[b]{2}{*}{ No } & \multirow{2}{*}{$\begin{array}{c}\text { No } \\
\text { Kelas }\end{array}$} & \multirow[b]{2}{*}{ Nama } & \multicolumn{3}{|c|}{ Centroid 1} & \multicolumn{3}{|c|}{ Centroid 2} & \multicolumn{3}{|c|}{ Centroid 3} & \multirow{2}{*}{$\begin{array}{c}\text { Centroid } \\
1\end{array}$} & \multirow{2}{*}{$\begin{array}{c}\text { Centroid } \\
2\end{array}$} & \multirow{2}{*}{$\begin{array}{c}\text { Centroid } \\
3\end{array}$} \\
\hline & & & $\begin{array}{c}301.0 \\
0\end{array}$ & \begin{tabular}{|c|}
26.0 \\
0 \\
\end{tabular} & 8.00 & $\begin{array}{c}18.4 \\
3\end{array}$ & \begin{tabular}{|c|}
2.2 \\
9 \\
\end{tabular} & 1.57 & $\begin{array}{c}124 . \\
0\end{array}$ & $\begin{array}{c}14.5 \\
0\end{array}$ & 5.00 & & & \\
\hline 1 & 0 & Karya Umum & & 199.61 & & & 84.14 & & & 22.50 & & & & Ok \\
\hline 2 & 100 & $\begin{array}{l}\text { Filsafat dan } \\
\text { Psikologi }\end{array}$ & & 155.26 & & & 128.63 & & & 22.50 & & & & Ok \\
\hline 3 & 200 & Agama & & 280.21 & & & 3.84 & & & 102.9 & & & Ok & \\
\hline 4 & 300 & IImu Sosial & & 269.08 & & & 14.60 & & & 91.81 & & & Ok & \\
\hline 5 & 400 & Bahasa & & 283.84 & & & 2.78 & & & 106.4 & & & Ok & \\
\hline 6 & 500 & Ilmu Murni & & 268.08 & & & 15.60 & & & 90.82 & & & Ok & \\
\hline 7 & 600 & IImu Terapan & & 0.00 & & & 283.64 & & & 177.4 & & Ok & & \\
\hline 8 & 700 & $\begin{array}{l}\text { Kesenian, } \\
\text { Hiburan, Olah } \\
\text { Raga }\end{array}$ & & 291.05 & & & 7.45 & & & 113.7 & & & Ok & \\
\hline 9 & 800 & Kesusastraan & & 293.13 & & & 9.53 & & & 115.8 & & & Ok & \\
\hline 10 & 900 & $\begin{array}{l}\text { Geografi dan } \\
\text { Sejarah Umum }\end{array}$ & & 300.10 & & & 16.48 & & & 122.7 & & & Ok & \\
\hline
\end{tabular}

Pada iterasi-1 sampai iterasi-4, rumus yang digunakan sama. Iterasi akan terus berlangsung sampai hasilnya konvergen. Dimana jika jarak data antara titik pusat yang sama pada suatu iterasi. Hasil percobaan ini dapat terlihat pada iterasi-3 dan iterasi-4, dimana anggota cluster pada iterasi-3 dan interasi-4 menunjukan hasil yang konvergen. 


\section{Kesimpulan dan Saran \\ 5.1 Simpulan}

Hasil penelitian menunjukkan bahwa pada Perpustakaan Utsman Bin Affan UMI belum menerapkan sistem komputerisasi secara maksimal, hal ini terlihat dengan masih digunakannya perhitungan secara manual dalam peyusunan data statistik peminjaman. Dengan adanya aplikasi pengelompokkan minat baca mahasiswa menggunakan metode klasterisasi pada Perpustakaan Utsman Bin Affan UMI, pengelolaan dan proses komunikasi dalam instansi menjadi lebih efektif, cepat dan tepat. Dimana aplikasi ini, memanage data buku yang dipinjam dan data buku yang dibaca. Tentunya data ini yang akan menjadi data olahan untuk proses klasterisasi k-means. Hasil klasterisasi dijadikan acuan untuk penambahan koleksi buku di perpustakaan.

\subsection{Saran}

Untuk penelitian yang sejenis dalam menggunakan metode klasterisasi (k-means), dapat digunakan beberapa variasi lain dari k-means. Dapat juga membandingan dengan metode klasterisasi lainnya, sehingga diperoleh hasil pemodelan yang maksimal. Sedangkan untuk pengembangan aplikasi disarankan untuk melakukan sinkronisasi dengan sistem yang ada secara real-time sehingga diperoleh data yang akurat.

\section{Daftar Pustaka}

[1] Agusta, Yudi. 2007. "K-Means - Penerapan, Permasalahan dan Metode Terkait”, Jurnal Sistem dan Informatika Vol.3. hal 47-60, Stikom Bali.

[2] C. Larasati Milburga, et.all. 1986. "Membina Perpustakaan Sekolah", Yogyakarta: Kanisius, hlm. 17

[3] Hasibuan, Zainal A, 2007, Metode Penelitian Pada Bidang Ilmu Komputer Dan Teknologi Informasi : Konsep, Teknik Dan Aplikasi, Jakarta : Fakultas

[4] Ibrahim, Adhi Yusran. 2014. "Penerapan Klasterisasi K-Means Dalam Penentuan Penerima Beasiswa Bidikmisi Pada Universitas Muslim Indonesia”. FTI, Teknik Informatika, Universitas Muslim Indonesia.

[5] J. C. Bezdek. 1981. "Pattern Recognition with Fuzzy Objective Function Algorithms". New York : Plenum Press. 